Davies, S. N. (1951). J. gen. Microbiol. 5, 807-816.

\title{
The Serology of Bacillus polymyxa
}

\author{
By SHEILA N. DAVIES
}

The Wellcome Research Laboratories, Beckenham, Kent

\begin{abstract}
SUMMARY: The spore, somatic and flagellar antigens of thirty-nine strains of Bacillus polymyxa have been investigated. The three antigens were serologically distinct and differed in thermal stability and in the appearance of the floccules after agglutination. The spore antigen was common to all the thirty-nine strains of $B$. polymyxa and appears to be species-specific. The somatic antigen was complex and absorption tests failed to show any clear-cut groups. On first isolation the organisms had flagellar antigens which were strain-specific, but after cultivation for some months on nutrient agar, an irreversible phase variation occurred which was associated with the appearance of group antigens. Five group-antigens have been recognized. One antigen was common to nearly all strains of $B$. polymyxa and also to the seven strains of $B$. macerans tested. Non-agglutinating antibodies were encountered in some flagellar antisera.
\end{abstract}

The only previous work on the serology of Bacillus polymyxa is by Porter, McCleskey \& Levine (1937). Using heated vegetative cells as antigens they found that no one antiserum agglutinated all the strains although some antisera agglutinated $60 \%$ of the strains tested. No cross-reactions with strains of $\boldsymbol{B}$. macerans were observed.

As part of a systematic study of the serology of the genus Bacillus an antigenic study of 39 strains of $B$. polymyxa has been made and the results are reported here.

\section{EXPERIMENTAL METHODS}

\section{Source of strains}

All the strains of the genus Bacillus used in this investigation were identified morphologically and biochemically by the methods described by Smith, Gordon \& Clark (1946). Twenty-nine of the 39 strains of $B$. polymyxa were isolated by Francis \& Rippon (1949). These strains were examined serologically immediately after isolation. Strains of the following species from the Wellcome Bacterial Collection were used in testing the B. polymyxa antisera for species specificity: $\boldsymbol{B}$. megatherium, $\boldsymbol{B}$. cereus, $\boldsymbol{B}$. cereus var. mycoides, $\boldsymbol{B}$. subtilis, B. subtilis var. atterimus, B. subtilis var. niger, B. pumilus, B. coagulans, B. firmus, B. lentus, B. macerans, B. circulans, B. pantothenticus, B. alvei, B. laterosporous, B. brevis, B. pasteurii, B. sphaericus, B. sphaericus var. fusiformis.

\section{Preparation of antigens for immunization of rabbits}

Somatic $(O)$ antigens were prepared from selected smooth colonies. A subculture from a smooth colony in nutrient broth was incubated overnight at $28^{\circ}$ and the growth resuspended in saline after centrifuging. The suspension 
was steamed for half an hour to destroy the $\mathbf{H}$ antigen and the opacity was adjusted to $8 \times 10^{8}$ organisms $/ \mathrm{ml}$. Cultures in broth were used in preference to agar cultures in order to avoid spore formation, which may occur during overnight incubation on agar, but has not been observed in broth even after several days' incubation.

Flagellar $(H)$ antigens were prepared from motile 18-hr. broth cultures preserved with $0.25 \%$ formalin (c. $0 \cdot 1 \%$ formaldehyde) and adjusted to the same opacity as the $O$ antigen. The motility was increased as necessary by inoculating a semi-solid agar plate at the circumference and, after overnight incubation, subculturing into nutrient broth from the spreading edge of growth.

Spore antigens were prepared from five-day nutrient agar slope cultures of $\boldsymbol{B}$. polymyxa which were examined microscopically to ensure that sporulation was complete. The growth was washed off the agar slopes with physiological saline and after steaming for $1 \mathrm{hr}$. was adjusted to $3 \times 10^{8}$ spores $/ \mathrm{ml}$. As $B$. polymyxa spores readily on nutrient agar, a suspension completely free from bacillary forms was easily obtained.

\section{Preparation of antisera}

Rabbits were injected intravenously at three-day intervals. Four doses of $1,2,3$ and $3 \mathrm{ml}$. respectively were given to produce $\mathbf{H}$ antisera and a further three or four injections of $3 \mathrm{ml}$. each for the production of $\mathrm{O}$ and spore antisera. The antisera were preserved with $50 \%(\mathrm{v} / \mathrm{v})$ of glycerol and $0.01 \%$ thiomersalate.

\section{Agglutinable suspensions}

The same procedure was followed as in the production of the antigens, except in the case of the $H$ suspensions, which were prepared from broth cultures incubated at $37^{\circ}$ instead of at $28^{\circ}$. Growth, though not so abundant at $37^{\circ}$, was less flocculent and gave stable suspensions for agglutination tests. Dense $\mathbf{H}$ suspensions for absorption tests were prepared from the growth on a semi-solid agar plate and preserved with $\mathbf{0 . 2 5} \%$ formalin. $\mathbf{H}$ and $\mathbf{O}$ suspensions of other species of the genus Bacillus were also prepared from semisolid agar plate cultures, as growth in broth often resulted in unstable suspensions. Spore suspensions of all species other than $B$. polymyxa were prepared from ten-day cultures on the asparagine medium described by Howie \& Cruickshank (1940). A medium consisting of equal parts of asparagine agar and nutrient agar was sometimes preferable, as in some cases growth on asparagine medium was asporogenous.

\section{Agglutination tests}

The agglutination tests were performed in $8 \times 1 \mathrm{~cm}$. agglutination tubes containing $0.5 \mathrm{ml}$. of serum in a series of twofold dilutions, mixed with an equal volume of bacterial suspension. The tests were incubated at $54^{\circ}$. The $\mathbf{H}$ agglutination tests were read after $2 \mathrm{hr}$. and the $O$ and Spore tests after overnight incubation. Incubation at $54^{\circ}$ was preferable to $37^{\circ}$, as at the latter 
temperature suspensions containing much mucinous material were inagglutinable. This was particularly noticeable when non-motile $O$ suspensions were not heated before use.

\section{Absorption tests}

Suspensions for absorption tests were of an opacity of $c .2 \times 10^{10}$ organisms $/ \mathrm{ml}$. Equal volumes of antiserum and suspensions were mixed and incubated for $2 \mathrm{hr}$. at $54^{\circ}$ and the absorbing suspension then removed by centrifugation. When the agglutinins to be absorbed were present in large amounts, the antiserum was diluted $1 / 10$ or 1/100 before the addition of the absorbing suspension.

\section{RESULTS}

The $H$ antisera had agglutination titres of $1 / 10,000$, the $O$ and Spore antisera $1 / 1,000$ or more. The three antigens were distinct and no cross-reactions could be demonstrated between them and their respective antibodies. Antisera prepared from formolized $\mathbf{H}$ suspensions contained a little somatic agglutinin for the homologous strain. This was to be expected, and, as shown in Table 1, the $\mathbf{O}$ agglutinin can be removed by absorption, leaving the $\mathbf{H}$ titre unaltered. Absorption tests, on the other hand, showed that agglutinins were only removed by the homologous antigen. These results were confirmed with a number of strains of B. polymyxa and are essentially the same as those obtained by other workers using different species of the genus (Howie \& Cruickshank, 1940; Lamanna, 1940a). Absence of bacillary agglutinins in the spore antisera is probably due to the ease with which completely-sporing suspensions free from bacillary forms can be prepared with this species. Rabbits injected with a spore suspension over a period of four months still failed to show any $\mathbf{O}$ agglutinins, although the spore titre was increased tenfold.

\section{Table 1. Reciprocal agglutinin absorption tests with B. polymyxa spore, $O$ and $H$ antisera and suspensions}

\begin{tabular}{|c|c|c|c|c|}
\hline \multirow{2}{*}{$\begin{array}{l}\text { Anti- } \\
\text { serum }\end{array}$} & \multirow{2}{*}{$\begin{array}{l}\text { Absorbing } \\
\text { suspension }\end{array}$} & \multicolumn{3}{|c|}{$\begin{array}{l}\text { Agglutination titres with the following } \\
\text { suspensions of the homologous strain }\end{array}$} \\
\hline & & Spore & $\mathbf{O}$ & $\mathbf{H}$ \\
\hline Spore & - & $* 1,600$ & $\mathbf{0}$ & 0 \\
\hline Spore & Spore & o & $\mathbf{0}$ & $\mathbf{0}$ \\
\hline Spore & O & 1,600 & $\mathbf{0}$ & $\mathbf{0}$ \\
\hline Spore & $\mathbf{H}$ & 1,600 & $\mathbf{0}$ & $\mathbf{0}$ \\
\hline $\mathbf{O}$ & - & o & 800 & $\mathbf{0}$ \\
\hline $\mathbf{O}$ & Spore & $\mathbf{0}$ & 800 & 0 \\
\hline O & O & o & 0 & 0 \\
\hline $\mathbf{0}$ & $\mathbf{H}$ & $\mathbf{0}$ & 800 & $\mathbf{0}$ \\
\hline $\mathbf{H}$ & - & $\mathbf{0}$ & 100 & 2,560 \\
\hline $\mathbf{H}$ & Spore & $\mathbf{0}$ & 100 & $\mathbf{2 , 5 6 0}$ \\
\hline $\mathbf{H}$ & O & $\mathbf{0}$ & $\mathbf{0}$ & 2,560 \\
\hline $\mathbf{H}$ & $\mathbf{H}$ & 0 & 0 & $\mathbf{0}$ \\
\hline
\end{tabular}

* The titre is expressed as the reciprocal of the highest antiserum dilution to show visible agglutination.

$0=$ No agglutination at an antiserum dilution of $1 / 10$. 
The appearance of the agglutination was characteristic for each of the three antigens. Floccular agglutination was characteristic of the $\mathbf{H}$ antigen and similar in appearance to that obtained with Salmonella $\mathbf{H}$ antisera and suspensions. The $\mathbf{O}$ and Spore agglutination was more granular and similar to the $S$. typhi $\mathrm{Vi}$ and $\mathbf{O}$ agglutinations, respectively. The $\mathbf{H}$ antigen also differed from the $\mathbf{O}$ and Spore antigens in being heat labile, being destroyed in $10 \mathrm{~min}$. at $100^{\circ}$ and inactivated by ethanol and chloroform. Saline suspensions of the $O$ and Spore antigens still retained their antigenicity in rabbits after being autoclaved for $20 \mathrm{~min}$. at $15 \mathrm{lb}$./sq. in. Similar results were obtained by Howie \& Cruickshank (1940) using the spore antigen of B. mesentericus, but they found that the antigenicity in vivo of the vegetative bacilli was completely destroyed by autoclaving.

\section{Spore antisera}

Spore suspensions of all 39 strains of $B$. polymyxa were agglutinated by the seven $\mathrm{S}$ antisera prepared and were capable of complete absorption of all the homologous agglutinins. No cross-reactions have so far been observed with spore suspensions of other species of the genus. Table 2 lists the numbers of strains and species used.

Table 2. B. polymyxa spore antiserum tested for specificity against spore suspensions of other species

Test suspension
species
B. polymyxa
B. polymyxa
B. megatherium
B. cereus
B. subtilis
B. licheniformis
B. pumilus
B. coagulans
B. firmus
B. lentus
B. macerans
B. circulans
B. alvei
B. laterosporous
B. brevis
B. sphaericus
B. pasteurii

Test suspension

B. polymyxa

B. polymyxa

B. megatherium

$B$. cereus

B. subtilis

B. licheniformis

B. pumilus

B. coagulans

B. firmus

B. lentus

B. macerans

B. circulans

B. alvei

B. laterosporous

B. sphaericus

B. pasteurii
Spore antiserum to

No. of strains
(1, CN 2002)
39
6
13
8
1
10
3
3
1
8
6
3
1
8
7
3

B. polymyxa CN 2002

titre

$1 / 800$

$1 / 400-1 / 800$

$<1 / 10$

$<1 / 10$

$<1 / 10$

$<1 / 10$

$<1 / 10$

$<1 / 10$

$<1 / 10$

$<1 / 10$

$<1 / 10$

$<1 / 10$

$<1 / 10$

$<1 / 10$

$<1 / 10$

$<1 / 10$

$<1 / 10$

\section{$O$ antisera}

O sera from 12 separate strains were prepared and the work of Porter et al. (1937) was in part confirmed. No one antiserum agglutinated all the strains tested, but a number of strains were agglutinated to $10 \%$ of the homologous titre and others to $100 \%$. On absorption no clear-cut groups could be demonstrated, but in most cases there was a strain-specific agglutinin present. 
Results of a typical agglutinin-absorption test are shown in Table 3. Brown, white and mucoid colonies described by Francis \& Rippon (1949) gave similar agglutination results. Suspensions from rough colonies, however, were inagglutinable with antisera prepared from smooth colonies. An antiserum prepared from one strain of $\boldsymbol{B}$. polymyxa in the rough phase agglutinated the rough variants of some strains of $B$. polymyxa but not those of other strains. Cross-reactions occurred between $O$ antisera and $O$ suspensions of a few strains of other species, including B. lentus, B. subtilis and B. macerans.

\section{Table 3. Representative agglutinin absorption tests with $\mathbf{B}$.} polymyxa $O$ antiserum prepared from strain $C N 2002$

\begin{tabular}{|c|c|c|c|c|c|c|c|c|}
\hline \multirow{2}{*}{$\begin{array}{c}\text { Test } \\
\text { suspension } \\
\text { (CN no.) }\end{array}$} & \multirow{2}{*}{$\begin{array}{c}\text { Un- } \\
\text { absorbed }\end{array}$} & \multicolumn{7}{|c|}{ Titre after absorption with $O$ suspensions of strains } \\
\hline & & $\mathrm{CN} 2002$ & CN 1419 & CN 1951 & CN 2135 & CN 2185 & CN 1756 & CN 2492 \\
\hline 2002 & *800 & $\mathbf{0}$ & 100 & 300 & 200 & 300 & 200 & 800 \\
\hline 1419 & 800 & $\mathbf{0}$ & $\mathbf{0}$ & $\mathbf{0}$ & 200 & 200 & $\mathbf{5 0}$ & 800 \\
\hline 1951 & 600 & $\mathbf{0}$ & $\mathbf{0}$ & $\mathbf{0}$ & 300 & $\mathbf{0}$ & $\mathbf{3 0 0}$ & 600 \\
\hline 2135 & 800 & o & 0 & 200 & 0 & 300 & 0 & 800 \\
\hline 2185 & 100 & 0 & 0 & 0 & 100 & O & 0 & 100 \\
\hline 1756 & 800 & 0 & 0 & 0 & 400 & 0 & o & 800 \\
\hline 2492 & 0 & 0 & 0 & 0 & 0 & 0 & o & 0 \\
\hline
\end{tabular}

\section{$H$ antisera}

$\mathrm{H}$ antisera were prepared from six freshly isolated strains. All these antisera agglutinated the homologous strain and no other. After maintaining these strains on nutrient agar for several months and then preparing fresh antisera for them, it was found that these new antisera agglutinated not only the homologous strain, but a number of other strains as well. The strains were kept as desiccates, some being dried immediately after isolation. These latter strains were still strain specific on subsequent recovery from the dried state. The recovered strains were plated and all the colonies appeared to be in the specific phase, but after a number of subcultivations on nutrient agar variation occurred, with the appearance of group antigens. Over a period of one year 35 of 39 strains showed this variation, which was not accompanied by any change in colonial appearance. This phase variation appeared to be irreversible. Attempts by the usual methods to obtain the specific variant from cultures in the group phase were unsuccessful. Table 4 illustrates this variation with five strains of $B$. polymyxa. The freshly isolated strains reacted only with their homologous serum, but these same strains after subcultivation on nutrient agar showed cross-reactions with other group antisera. It can be seen from Table 4 that in most instances the strain in the group phase still contained some specific antigen. However, with the strains CN 1419 and CN 1966 the variation was complete, the subcultivated strain containing only the group antigens. In strain CN 1966 there was an intermediate stage before 


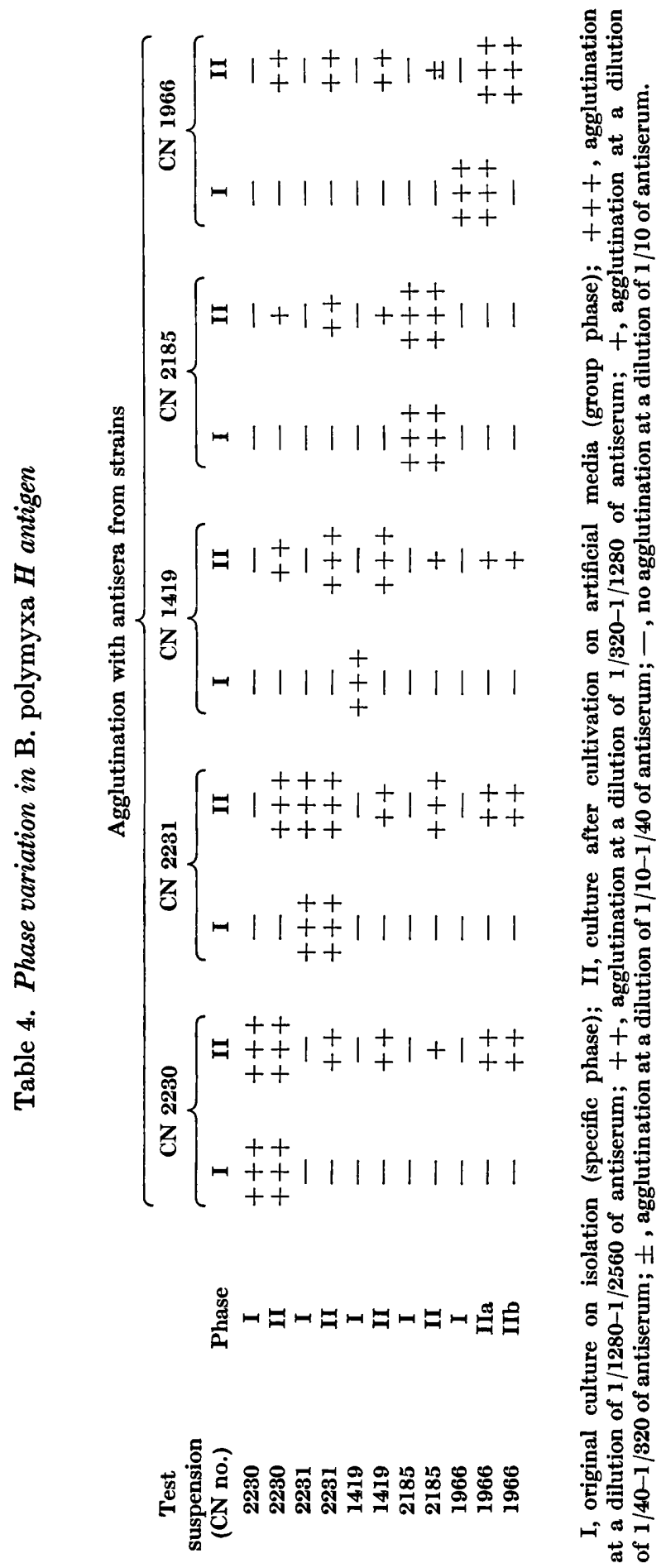


the appearance of colonies containing only group antigens, when all colonies contained both specific and group antigens. This is represented by strain CN 1966 IIa in Table 4. Suspensions of organisms in the specific phase were incapable of removing group antigens by absorption. Suspensions of organisms in the group phase varied in their ability to remove agglutinins from antisera prepared against the specific phase depending on the extent to which variation had occurred. At least five group antigens have been recognized by absorption tests on antisera prepared from 22 strains in the group phase. One group antigen appears to be common to nearly all $B$. polymyxa strains tested, others are shared by two or more strains. A number of group antigens may be present in one strain. The results obtained by absorption tests are illustrated in Table 5, where it is shown that the antiserum prepared from $B$. polymyxa strain $\mathrm{CN} 2231$ in the group phase contains some specific antibody and three group antigens, labelled for convenience A, B and C. Absorption tests showed that, of eight strains of $\boldsymbol{B}$. polymyxa, one strain contained group antigen $\mathbf{A}$, the group antigen common to most strains of $B$. polymyxa. Four strains contained group antigens $\mathbf{A}$ and $\mathbf{B}$, and three strains contained antigens $\mathbf{A}$ and C. Two strains of B. macerans contained antigen A. These agglutination reactions were due to the flagellar agglutinating system, since the appearance of the floccules was characteristic and the agglutinability and absorbing power of the suspensions were lost when they were heated in a boiling water-bath for ten minutes.

Table 5. Absorption tests on B. polymyxa $C N 2231 \mathrm{H}$ group antiserum

\begin{tabular}{|c|c|c|c|c|c|c|c|}
\hline \multirow{2}{*}{$\begin{array}{c}\text { Suspensions } \\
\text { of strains } \\
\text { (CN no.) }\end{array}$} & \multirow{2}{*}{$\begin{array}{l}\text { Group anti- } \\
\text { gens present } \\
\text { in suspension }\end{array}$} & \multirow{2}{*}{$\begin{array}{c}\text { Un- } \\
\text { absorbed }\end{array}$} & \multirow{2}{*}{$\begin{array}{l}\text { Absorbed with } \\
\text { CN 2231 in } \\
\text { group phase }\end{array}$} & \multicolumn{4}{|c|}{$\begin{array}{l}\text { Absorbed with a mixture of strains } \\
\text { containing group antigens* }\end{array}$} \\
\hline & & & & $\mathbf{A}$ & A, $\mathbf{B}$ & $\mathrm{A}, \mathrm{C}$ & $A, B, C$ \\
\hline 2231 & $\begin{array}{c}\text { None (specific } \\
\text { phase) }\end{array}$ & $+t$ & - & $+\dagger$ & $+\dagger$ & $+t$ & $+t$ \\
\hline 2231 & $\mathrm{~A}, \mathbf{B}, \mathbf{C}$ & +++ & - & ++ & ++ & ++ & ++ \\
\hline $\left.\begin{array}{l}1013 \ddagger \\
1014 \\
2230\end{array}\right\}$ & $\mathbf{A}$ & $\begin{array}{l}+++ \\
+++ \\
+++\end{array}$ & E & - & E & E & - \\
\hline $\left.\begin{array}{l}1756 \\
1419 \\
2002 \\
2228\end{array}\right\}$ & $A, B$ & $\begin{array}{l}+++ \\
+++ \\
+++ \\
+++\end{array}$ & $\begin{array}{l}- \\
\text { - }\end{array}$ & $\begin{array}{l}++ \\
++ \\
++ \\
++\end{array}$ & $\begin{array}{l}- \\
- \\
-\end{array}$ & $\begin{array}{l}++ \\
++ \\
++ \\
++\end{array}$ & $\begin{array}{l}- \\
-\end{array}$ \\
\hline $\left.\begin{array}{l}2185 \\
2180 \\
2135\end{array}\right\}$ & $\mathrm{A}, \mathrm{C}$ & $\begin{array}{l}+++ \\
+++ \\
+++\end{array}$ & - & $\begin{array}{l}++ \\
++ \\
++\end{array}$ & $\begin{array}{l}++ \\
++ \\
++\end{array}$ & E & 二 \\
\hline
\end{tabular}

* Mixture of strains used for absorption were the same strains as those shown in the lefthand column under their respective antigenic groups.

$\uparrow$ Traces of specific agglutinin in the group phase serum of CN 2231 .

$\ddagger \mathrm{CN} 1013,1014$ were strains of $B$. macerans, all other strains were $B$. polymyxa.

Cross-reactions between the B. polymyxa phase II antisera and H suspensions of other species of the genus Bacillus other than $B$. macerans have been observed, but only with a few strains of different species. These strains also reacted with sera prepared from strains of species other than $B$. polymyxa. 
As the non-reacting strains were only agglutinated by their homologous sera, it seemed likely that these cross-reacting strains had already undergone the same kind of variation as occurs in B. polymyxa.

\section{Non-agglutinating antibodies}

During the preparation of group antisera from a number of different subcultures of the same strain, a phenomenon was observed for which no satisfactory explanation is offered. This effect is illustrated in Table 6. Antiserum A from CN1419 in the group phase behaved normally and it was apparent that the seven other strains tested were of the same antigenic type. Absorption of the antiserum with any one strain removed the agglutinins to all the

Table 6. Non-agglutinating antibodies in serum prepared from CN1419 and 2002 in the group phase. Absorption tests with strains of the same serological group

\begin{tabular}{|c|c|c|c|c|c|c|c|c|c|}
\hline \multirow[b]{2}{*}{$\begin{array}{c}\text { Anti- } \\
\text { serum } \\
\text { (CN no.) }\end{array}$} & \multirow[b]{2}{*}{$\begin{array}{l}\text { Absorb- } \\
\text { ing } \\
\text { strains }\end{array}$} & \multicolumn{8}{|c|}{ Test suspension } \\
\hline & & $\begin{array}{c}1 \\
\text { CN } \\
1419\end{array}$ & $\underset{1756}{2}$ & $\begin{array}{c}3 \\
\text { CN } \\
2228\end{array}$ & $\begin{array}{c}4 \\
\text { CN } \\
2184\end{array}$ & $\begin{array}{c}5 \\
\mathrm{CN} \\
2222\end{array}$ & $\begin{array}{c}6 \\
\text { CN } \\
2369\end{array}$ & $\begin{array}{c}7 \\
\mathbf{C N} \\
2370\end{array}$ & $\begin{array}{c}8 \\
\mathrm{CN} \\
2002\end{array}$ \\
\hline $\begin{array}{l}1419 \mathrm{~A} \\
1419 \mathrm{~A}\end{array}$ & $\begin{array}{l}\text { none } \\
*_{1-8}\end{array}$ & ++ & ++ & $\underline{t+}$ & $+t+$ & $\underline{t+}$ & $+\underline{+}$ & ++ & $\underline{++}$ \\
\hline 1419 B & none & +++ & \pm & - & - & - & - & - & - \\
\hline $1419 \mathrm{~B}$ & $1-8$ & - & - & - & - & - & - & - & - \\
\hline 2002 & none & - & - & - & - & - & - & - & +++ \\
\hline 2002 & $1-8$ & - & - & - & - & - & - & - & - \\
\hline
\end{tabular}

- 1-8 implies eight experiments in which the serum was absorbed by each strain separately. +++ , agglutination at a dilution of 1/1280-1/2560 of antiserum; ++ , agglutination at a dilution of 1/320-1/1280 of antiserum; + , agglutination at a dilution of $1 / 40-1 / 320$ of antiserum; \pm , agglutination at a dilution of 1/10-1/40 of antiserum; - , no agglutination at a dilution of $1 / 10$ of antiserum.

others. However, with antiserum B prepared from a different subculture of CN1419 in the group phase, agglutination was obtained only with the homologous strain and low titre agglutination with one other, strain CN1756. At first sight it appeared that the strain had reverted to the specific phase, but although the other strains were not agglutinated by the serum, they were capable of absorbing all the agglutinins. The strains which failed to agglutinate were also inagglutinable in the presence of $30 \%$ bovine albumin or $10 \%$ rabbit-serum. Blocking antibody of the type described by Griffitts (1947) for Brucella was, therefore, not present. Results of tests for incomplete antibody using hen anti-rabbit precipitating serum (Coombs, Mourant \& Race, 1945; Morgan \& Schütze, 1946) were equivocal. In some instances agglutination was obtained with anti-rabbit precipitating serum, but the method was not practical, due to the necessity of washing these suspensions free from rabbit serum while still retaining the flagella. A blocking test was carried out to see whether the normal agglutination between $\mathrm{CN1419} A$ antiserum and $H$ suspensions of strains $\mathrm{CN} 2228$ and $\mathrm{CN} 2184$ could be prevented by previously incubating the suspensions with CN1419 B antiserum. After $2 \mathrm{hr}$. incubation 
with CN1419 B antiserum the suspensions were centrifuged, the deposit resuspended in saline and added to a dilution of $\mathrm{CN} 1419 \mathrm{~A}$ antiserum. The suspensions were agglutinated to titre as before, with no trace of blocking effect.

\section{DISCUSSION}

By careful attention to cultural conditions, it is possible to prepare from strains of $\boldsymbol{B}$. polymyxa suspensions which are suitable for agglutination tests and for differentiation of the spore, somatic and flagellar antigens. Under these conditions the Spore, $\mathrm{O}$ and $\mathrm{H}$ antigens have been shown to be distinct, thus confirming the observations of Mellon \& Anderson (1919), Howie \& Cruickshank (1940), and Lamanna (1940a), on other species of the genus. There has been little systematic serological investigation of the genus Bacillus. Lamanna (1940 $a$ ), however, studied the spore antigens of several strains of B. subtilis, 'B. vulgatus', 'B. mesentericus' and 'B. agri' and found that they could be divided into three well-defined serological groups. From the details in Lamanna's paper of their biochemical reactions, it seems likely that these organisms could be reclassified as : B. licheniformis, B. subtilis and B. pumilus (see Smith, Gordon \& Clark, 1946; Knight \& Proom, 1950). Each species has then a distinctive spore antigen. Lamanna $(1940 a)$ reported that the spore antigen appeared to be less complex than the bacillary antigens. Although Lamanna's results (1940 b) with the spore antigens of the 'large-celled species' were less clear-cut, he suggested that a serological analysis would be of use in classification. The present work on $B$. polymyxa has shown that this species has a complex antigenic structure. The flagellar and somatic antigens are too numerous and complex to be of value in classification, but the spore antigen appears to be species-specific and of definite taxonomic value.

Heated spores were used as antigens in preference to living spores in order to avoid the formation of high-titre $\mathbf{H}$ agglutinins which were present in living-spore antisera after one injection. No $\mathrm{O}$ agglutinins could be demonstrated. The formation of $\mathbf{H}$ agglutinins may be due to the presence in the spore suspension of a few bacilli containing the highly antigenic $\mathbf{H}$ antigen. Krauskopf \& McCoy (1937) working with strains of $B$. subtilis var. niger and Doak \& Lamanna (1948) with B. cereus showed that the $H$ antigen is present in the spore, but $\mathbf{H}$ agglutinins were only produced after the spores had been treated with potassium hydroxide. Whether or not the $\mathrm{H}$ agglutinins in the $B$. polymyxa living-spore antiserum are derived from the spore has not been ascertained. It seems likely that a study of the spore antigens covering the whole of the genus could be of considerable value; such work is now in progress.

The flagellar and somatic antigens of B. polymyxa appear to be too numerous to be of practical use in classification. The flagellar antigens can exist in both the specific and group phases. The somatic antigens are complex and several may exist together in one strain. Both $\mathbf{O}$ and $\mathbf{H}$ antigens may be shared by strains of $\boldsymbol{B}$. macerans. It would be possible to characterize a number of different antigenic types in the $\mathrm{O}$ and $\mathrm{H}$ antigens, but such work would be of little practical value. Any grouping of strains by means of the $\mathrm{O}$ antigens has shown no relationship to the grouping based on bacteriophage sensitivity 
(Francis \& Rippon, 1949), or to the type of polymyxin produced (Brownlee \& Jones, 1948).

Several points of interest have arisen from the results with flagellar antigens. With organisms freshly isolated from the soil, the flagellar antigen is invariably in the specific phase, but after the organism has been maintained on nutrient agar, an irreversible phase variation occurs, the speed of change depending on the strain. Some strains have undergone variation after a few subcultures while others remained in the specific phase after eight months' subcultivation at weekly intervals. There also appears to be another reaction occurring in the flagellar antigen which is responsible for the production of a type of 'non-agglutinating antibody'. This antibody combines with and agglutinates the homologous strain and can combine with, but not agglutinate, other strains of the same group phase. A serum may agglutinate some strains but not others, or may only agglutinate the homologous strain. No explanation is offered for this effect. It is not an 'incomplete antibody' in the true meaning of the term, since agglutination does not occur in the presence of $30 \%$ albumin and agglutination always occurs with the homologous strain.

I am indebted to Dr A. E. Francis and Mr H. Proom for their advice and criticism and to Mrs J. A. Birkbeck for technical assistance.

\section{REFERENCES}

Brownlee, G. \& Jones, T. S. G. (1948). The polymyxins; a related series of antibiotics derived from $B$. polymyxa. Biochem. J. 43, xxv.

Coombs, R. R. A., Mourant, A. E. \& Race, R. R. (1945). New test for detection of weak and 'incomplete' Rh agglutinins. Brit. J. exp. Path. 26, 225.

Doak, B. W. \& Lamanna, C. (1948). On the antigenic structure of the bacterial spore. J. Bact. 55, 373.

Francis, A. E. \& Rippon, J. E. (1949). Bacillus polymyxa and its bacteriophages. J. gen. Microbiol. 3, 425.

GrIFFTTTS, J. J. (1947). Agglutination and an agglutin-'blocking' property in serum of known cases of Brucellosis. Publ. Hlth Rep., Wash. 62, 865.

Howie, J. W. \& Cruickshank, J. (1940). Bacterial spores as antigens. J. Path. Bact. 50, 235.

KNight, B. C. J. G. \& Proom, H. (1950). A comparative survey of the nutrition and physiology of mesophilic species in the genus Bacillus. J. gen. Microbiol. 4, 508.

KraUsKopf, E. J. \& McCoy, E. (1937). The serology of spores of Bacillus niger with special reference to the $\mathrm{H}$ antigen. J. infect. Dis. 61, 251.

Lamanna, C. (1940 a). The taxonomy of the genus Bacillus. Differentiation of smallcelled species by means of spore antigens. J. infect. Dis. 67, 193.

Lamanna, C. $(1940 \mathrm{~b})$. The taxonomy of the genus Bacillus. Differentiation of large-celled species by means of spore antigens. J. infect. Dis. 67, 205.

Mellon, R. R. \& Anderson, L. M. (1919). Immunologic disparities of spore and vegetative stages of Bacillus subtilis. J. Immunol. 4, 203.

Morgan, W. T. J. \& Schürze, H. (1946). Non-agglutinating antibody in human antisera to Sh. shiga and S. typhi. Brit. J. exp. Path. 27, 286.

Porter, R., McCleskey, C. S. \& Levine, M. (1937). The facultative sporulating bacteria producing gas from lactose. J. Bact. 33, 162.

Smith, N. R., Gordon, R. E. \& Clark, F. E. (1946). Aerobic mesophilic sporeforming bacteria. Mis. Publ. U.S. Dep. Agric. no. 559.

(Received 13 Janaury 1951) 